\title{
Production of Biodiesel from Waste Cooking Oil by Transesterification Process using Heterogeneous Catalyst
}

\author{
Salihu A. ${ }^{1, *}$, Mahmood A. A. ${ }^{2}$, Gimba S. B. ${ }^{1}$, Nzerem P. ${ }^{1}$ and Okafor I. ${ }^{1}$ \\ ${ }^{1}$ Department of Petroleum and Gas, Faculty of Engineering, Nile University of Nigeria, Abuja, Nigeria \\ ${ }^{2}$ Department of Chemistry, Faculty of Engineering, Nile University of Nigeria, Abuja, Nigeria \\ Corresponding Author: *a.salihu@ nileuniversity.edu.ng
}

https://doi.org/10.36263/nijest.2021.02.0308

\begin{abstract}
Non-renewable diesel from fossil has been considered as potentially carcinogenic with serious harmful effect to human health and to the environment. This study aimed to produce a renewable diesel-biodiesel-via transesterification of waste cooking oil (WCO), investigated and determined the most suitable amongst various types of heterogenous catalysts (viz a viz $\mathrm{KOH} / \mathrm{CaCO}$, $\mathrm{KOH} / \mathrm{CaO}$ and $\mathrm{KOH} / \mathrm{K}_{2} \mathrm{CO}_{3}$ ). The chemical and physical characterisation of the biodiesel was been carried out. Among the catalysts investigated, $\mathrm{KOH} / \mathrm{CaCO}$ catalyst showed the best catalytic performance in terms of \% yield and better fuel quality in density, acid value, viscosity and free fatty acid. The reason for this performance may be due to its most basic characteristic than the others. As a result, this catalyst was selected for the optimisation study. At the optimum reaction conditions of $10 \mathrm{wt} \%$ catalyst loading and 1:10 oil to methanol feed mole ratio, triglycerides conversion was highest, $98.12 \%$. The characterisation results shows that the parameters tested (i.e. density, viscosity, acid value and free fatty acid) meet the strict requirements of the biodiesel standard and therefore, the produced fuel can be used in place of the petrol diesel.
\end{abstract}

Keywords: Biodiesel, Waste cooking oil, Transesterification, WCO, Heterogeneous catalyst

\subsection{Introduction}

Energy is an essential aspect of human society and can be derived from renewable and non-renewable sources. The renewable energy resources are considered as a green and clean source of energy that replenishes naturally from solar, wind, biomass, geothermal, etc. While non-renewable energy resources are energy that cannot be replenished in a reasonable amount of time, examples are fossil fuel and nuclear energy. Currently, significant growth in population and change in lifestyle has led to increase in energy consumption with fossil resources as major source of this increase in energy demand. Globally, primary energy consumption has increased nearly every year for at least half a century. But this is not the case everywhere in the world. Energy consumption is rising in many countries where incomes are rising quickly and the population is growing. But in many countries particularly richer countries trying to improve energy efficiency - energy consumption is actually falling. In Nigeria, the total energy consumption increases by 3\% per annum between 2010-2020 (Africa Energy World Report, 2019).

Considering Nigeria as a case study with large deposit of crude oil, energy from petroleum products has been the easiest and most utilized source of fuel. Nevertheless, the energy crisis experienced in other parts of the world is also experienced here. Due to the country's large population and owing to diversion of the products to neighbouring countries, the existing capacity of the refineries in the country cannot meet demand; ironically the finished petroleum fuels are imported into the country. Furthermore, pollution via gas flaring, continuous oils spills which have been occurring from time to time and crisis in the oil producing communities towards the struggle for a fair share of the proceeds from the exploitation of crude oil are some of the problems. In addition, there are issues of oil bunkering and illegal oil refineries in and around the Niger Delta area as well (Tombari et al., 2020). 
These economic, environmental and political issues have resulted in growing interest in alternative engine fuels, such as biodiesel.

Fossil fuels are unsustainable source of producing energy in terms of cost of conversion, environmental pollution, non-renewable and political problems (Phebe and Samuel, 2016).

Also, it is believed that combustion of fossil fuels is the principal cause of global warming (Tombari et al., 2020). Based on these facts and many more, there has been focus on energy generation from cleaner and sustainable resources in the world today. Thus, to resolve the problem of fossil fuels depletion and increase in the price of energy due to high rate of demand, biofuel technology has been accepted as an alternative replacement for conventional fossil fuel (Anwar et al., 2021).

Biodiesel holds great potential as an alternative energy sources that are renewable, economically feasible and friendly to the environment (Muhammad et al., 2018). In solving the problem of environmental crisis currently experienced all over the world due to energy generation, biodiesel production has become the focus of many investigations. This is because of its better quality of exhaust gas emissions, biodegradability and, it does not contribute to a net rise in the level of pollution through the release of carbon dioxide in the atmosphere (Choi, 2019).

Biodiesel, liquid biofuel from vegetable oils or animal fats, seems to be a promising alternative to fossil fuels. This is because the feedstock required for the production of biodiesel is accessible in large quantity. Its production involves simple procedures making biodiesel easily available. Also, biofuel is renewable, sustainable and environmentally friendly. In addition, its usage is compatible with petroleum-diesel engine (Subramaniam et al., 2020; Muhammad et al., 2018).

However, high yield and high-quality biodiesel can only be achieved through scientific assessment of production process (Chozhavendhan, 2020). Biodiesel can be produced from transesterification process which involves a chemical reaction between plant oil/animal fat and alcohol (such as methanol) in the presence of a catalyst (such as $\mathrm{KOH}$ ) to give biodiesel and glycerol. The assessment of biodiesel production includes the use of different feedstocks for biodiesel production (in order to evaluate such feedstocks in terms of their yields), consideration of the most suitable alkali catalyst, consideration of the effect of varied factors of production and establishment of optimum conditions for biodiesel production (Subramaniam et al., 2020).

According to Felix et al. (2020), biodiesel is conceived to be a mono alkyl ester of long chain fatty acids derived from a renewable lipid feedstock. Their main drawback is price, which is higher than crude oil-derived diesel. The high cost of vegetable oils, which could be up to $75 \%$ of the total manufacturing cost, has led to the production costs of biodiesel becoming approximately 1.5 times higher than that for diesel (Yang et al., 2019;). Nevertheless, the price of waste cooking oils (WCO) is 2-3 times cheaper than neat vegetable oils. Therefore, the total manufacturing cost of biodiesel can be significantly reduced (Yang et al., 2019). In addition, it is on the record that every year: many millions of tons of waste cooking oil are collected and utilized in a variety of ways throughout the world (Michael et al., 2019). This used oil that nonetheless contains foreign material are often disposed in manners that contaminate our soil and water. Hence, the proper management and utilization of waste cooking oil from domestic and business sources would pave way for a clean environment, serves as a veritable source of renewable energy and reduce the nation's overdependence on fossil fuel. In addition, the utilization of waste vegetable oils reduces pollution problems as reusing of these waste oil decreases the burden of the government in disposing of the waste, maintaining public sewers, and treating the oil wastewater. The fact is, so far, that only a very small percentage of these oils has been collected and utilized for purpose such as soap production. We therefore investigated and determined the most suitable amongst various types of heterogenous catalysts - viz a viz $\mathrm{KOH} / \mathrm{CaCO}_{3}, \mathrm{KOH} / \mathrm{CaO}$ and $\mathrm{KOH} / \mathrm{K}_{2} \mathrm{CO}_{3}$ - for the production of biodiesel. 


\subsection{Methodology}

\subsection{Properties of the oil samples}

\subsubsection{Determination of density}

Density is the mass per unit volume of any liquid at given temperature. The density of the oil sample at room temperature was determined using the formula below:

Density $=\frac{\text { mass }}{\text { volume }}$

\subsubsection{Determination of acid value and free fatty acid (FFA) content}

The acid number is a measure of the number of carboxylic acid groups in a chemical compound, such as a fatty acid, or in a mixture of compounds.

\section{Procedure:}

In a typical procedure, $2 \mathrm{~g}$ of oil sample was dissolved in a mixture of organic solvents, $\mathrm{n}$-hexane, and ethanol (2:1) to form a single phase solution. Two drops of phenolphthalein indicator were added to the resulting solution, and the solution was titrated with $0.1 \mathrm{M}$ solution of potassium hydroxide until a pink coloured solution was established. Each titration was repeated four times and the standard deviation calculated. The acid value and FFA are defined as equation:

Acid value $(\mathrm{mg} \mathrm{KOH} / \mathrm{g}$ sample $)=\frac{C(V-b) \times 56.1}{m}$

FFA $(\%)=\frac{C(V-b) \times 27.81}{m}$

Where $V$ and $b$ is the consumed volume ( $\mathrm{ml})$ of $\mathrm{KOH}$ and blank used for titration respectively, $C$ is the concentration of $\mathrm{KOH}\left(\mathrm{mol} / \mathrm{dm}^{3}\right)$, and the $\mathrm{m}$ is the mass of the tested sample $(\mathrm{g})$ and 56.1 is the molecular weight of $\mathrm{KOH}$. The value of 27.81 used in the determination of FFA was obtained from the average molecular mass of fatty acids divided by ten. For this research work, the average molecular mass of fatty acids is $278.11 \mathrm{~g} \mathrm{~mol}^{-1}$. If the molecular mass of fatty acids remains unknown, this value is referred to as one-tenth of the molecular mass of oleic acid (Özbay et al., 2008; Bianchi et al., 2010).

\subsubsection{Determination of viscosity}

Kinematic viscosity (v) is mathematically defined as:

$v=\frac{\mu}{p}$

Viscosity is closely related with the fatty acid composition of a given oil sample, it increases with increasing length of the fatty acid chain that also relates to the rate of transesterification reaction of a given oil sample. The major aim of these reactions is to reduce the viscosity values of the triglycerides (before transesterification) and biodiesel (Fatty Acid Methyl Ester, FAME) produced (after reaction) since the major drawback of using neat vegetable oils as fuels are due to the high viscosity values they possess. This viscosity difference forms the basis of an analytical method (viscometry) applied to determine the conversion of vegetable oils to methyl esters. The viscosity difference between the component triglycerides and their corresponding methyl esters resulting from transesterification is approximately one digit (Knothe, 2001).

\section{Procedure:}

The dynamic viscosity of the oil samples will be determined using any available viscometer at a temperature of $40^{\circ} \mathrm{C}$. Replicate measurements will be done until the instrument gives consistent results. 


\subsubsection{Water content}

The water content is determined by means of a so-called heating curve that is recorded at a heating rate of $2{ }^{\circ} \mathrm{C} / \mathrm{min}$ over the temperature range 50 to $250{ }^{\circ} \mathrm{C}$. In the heating curve, the amount of released water per unit time (drift) is plotted as a function of the oven temperature. Studies show that diesel sample releases its water content between 50 and $110{ }^{\circ} \mathrm{C}$.

\subsection{Catalyst preparation}

\subsubsection{Preparation of the heterogeneous $(\mathrm{KOH} / \mathrm{X})$ catalysts}

The $\mathrm{KOH} / \mathrm{X}\left(\mathrm{X}=\mathrm{CaCO}_{3}, \mathrm{~K}_{2} \mathrm{CO}_{3}, \mathrm{CaO}\right)$ catalysts were prepared using wet impregnation method as reported by Kotwal et al. (2009). To prepare the different catalyst systems of the neutral salt and the support X, $0.25 \mathrm{~g}, 0.5 \mathrm{~g}, 0.75 \mathrm{~g}$ and $1.0 \mathrm{~g}$ of $\mathrm{KOH}$ pellet equivalent to $5 \%, 10 \%, 15 \%$ and $20 \%$ respectively to the $5 \mathrm{~g}$ of the support catalyst $\mathrm{X}\left(\mathrm{X}=\mathrm{CaCO}_{3}, \mathrm{~K}_{2} \mathrm{CO}_{3}, \mathrm{CaO}\right)$ were weighed accurately and dissolved in $50 \mathrm{ml}$ of distilled water. The supported catalyst, in each case, was added to the $\mathrm{KOH}$ solution. The solution was then constantly stirred continuously using magnetic stirrer on a hot plate $\left(80{ }^{\circ} \mathrm{C}\right)$ until homogeneous mixtures was obtained. The removal of water was accomplished by using rotary evaporator then drying in an oven at $100{ }^{\circ} \mathrm{C}$ for $2 \mathrm{~h}$, and then calcined in a muffle furnace at $500{ }^{\circ} \mathrm{C}$ for $5 \mathrm{~h}$ in air. The obtained catalyst was then characterized using Fourier transform infrared spectroscopy (FTIR) techniques to determine the formation and effect of the $\mathrm{KOH}$ loading on

\subsection{Transesterification process of vegetable oils to fatty acid methyl esters (FAME)}

Experiments were conducted using a reflux fitted system in which the mixture of WCO, methanol, and catalyst were added together in a $500 \mathrm{ml}$ three-necked flask and heated up to the desired temperature $\left(60-70^{\circ} \mathrm{C}\right)$ on the hot plate. The catalyst loading used were taken as $3 \mathrm{wt} \%, 5 \mathrm{wt} \%, 10 \mathrm{wt} \%$, $15 \mathrm{wt} \%$ and $20 \mathrm{wt} \%$ with a constant mass of oil of $50 \mathrm{~g}$, and oil/methanol molar ratios of 1:3, 1:5, 1:10, 1:20 and 1:30. The reaction was continuously agitated/stirred for $5 \mathrm{~h}$. When the reaction reached the pre-set reaction time, the heating and stirring were then stopped.

\subsection{Crude biodiesel purification}

After obtaining the optimum point, the crude biodiesel was purified by washing it with $30 \%$ (by volume of the feedstock) of distilled water using a separation funnel. Since both glycerol and methanol are highly soluble in water, crude biodiesel was mixed with distilled water and agitated gently to avoid the formation of emulsion, then slowly percolating droplets of water through the ester (Atadashi et al., 2011). The process was repeated until colourless wash water was obtained, indicating complete removal of impurities.

\subsection{Product estimation}

The yield and conversion were calculated as follows:

$$
\begin{aligned}
& \text { Yield (\%) }=\frac{\text { Weight }_{\text {Biodiesel }}}{\text { Weight }_{\text {Oil }}} \times 100 \\
& \text { Conversion }(\%)=\frac{\text { Weight }_{\text {Triglyceride }}-\text { Weight }_{\text {Biodiesel }}}{\text { Weight }_{\text {Triglyceride }}} \times 100
\end{aligned}
$$

Where the weight of triglyceride was taken as the initial mass of oil, which was $50 \mathrm{~g}$.

\subsection{Characterisation of biodiesel}

i. This entails laboratory tests conducted to confirm and establish the properties and quality of the methyl esters (biodiesel) obtained under optimal conditions (under the different catalytic processes). The results are compared to biodiesel fuel standards based on European Union quality standard (EN 14214, 2003), American standard tests and measurements ASTM D 6751 (ASTM, 2020a) specifications. Various laboratory tests that can be carried out on the biodiesel samples include the following: 
ii. viscosity at a particular temperature (e.g. $40^{\circ} \mathrm{C}$ and $100^{\circ} \mathrm{C}$ ) with ASTM D7279 (ASTM, $2020 \mathrm{~b}$ ) test method to indicate the resistance of the fuel to flow at $40^{\circ} \mathrm{C}$ and $100^{\circ} \mathrm{C}$;

iii. density at $20^{\circ} \mathrm{C}$ with ASTM D4052 (ASTM, 2019) test method;

iv. flashpoint with ASTM D93 (ASTM,2020c) test method;

v. appearance/colour;

vi. pour point and cloud point obtained using ASTM D92 (ASTM, 2018) test method;

vii. acid number with ASTM D974 (ASTM, 2017) test method to determine the acidity of the fuel (lubricant);

The obtained results for any of this parameter will be compared with the reported properties of common biodiesel.

\subsection{Results and Discussions}

\subsection{Results}

The analysis of the properties of waste cooking oil as well as the properties of biodiesel with different concentration of $\mathrm{KOH} / \mathrm{X}$ support catalyst with 1:3 oil/methanol ratio are presented in Tables 1 to 6 ; in addition yields obtained from transesterification with the $10 \%$ catalyst are also presented.

Table 1: Properties of the waste cooking oil

\begin{tabular}{lll}
\hline Property & WCO & Neat Palm Oil* \\
\hline Density $\left(\mathrm{g} / \mathrm{cm}^{3}\right)$ & 0.92 & 0.90 \\
Acid Value $(\mathrm{mg} \mathrm{KOH} / \mathrm{g})$ & 1.57 & $<0.5$ \\
Water Content $(\%)$ & 0.84 & 0.05 \\
Viscosity $\left(\mathrm{mm}^{2} / \mathrm{s} \mathrm{@} 40^{\circ} \mathrm{C}\right)$ & 31.20 & 30.2 \\
Free fatty acid (wt\%) & 3.04 & $<0.5$ \\
\hline \multicolumn{2}{r}{ *(Leung et al., 2006) }
\end{tabular}

Table 2: Properties of biodiesel obtained with $5 \% \mathrm{KOH} / \mathrm{X}$ support catalyst with 1:3 oil/methanol ratio

\begin{tabular}{llll}
\hline Properties & $\mathrm{KOH} / \mathrm{CaCO}_{3}$ & $\mathrm{KOH} / \mathrm{CaO}$ & $\mathrm{KOH} / \mathrm{K}_{2} \mathrm{CO}_{3}$ \\
\hline Density $\left(\mathrm{g} / \mathrm{cm}^{3}\right)$ & 0.82 & 0.86 & 0.78 \\
Acid Value $(\mathrm{mg} \mathrm{KOH} / \mathrm{g})$ & 0.68 & 0.87 & 1.50 \\
Viscosity $\left(\mathrm{mm}^{2} / \mathrm{s} \mathrm{@} \mathrm{40} 0^{\circ} \mathrm{C}\right)$ & 2.60 & 2.80 & 2.12 \\
Free fatty acid $(\%)$ & 6.187 & 2.87 & 2.37 \\
Yield $(\%)$ & 45.77 & 29.41 & 13.11 \\
\hline
\end{tabular}

Table 3: Properties of biodiesel obtained with $10 \% \mathrm{KOH} / \mathrm{X}$ support catalyst with 1:3 oil/methanol

\begin{tabular}{llll}
\multicolumn{3}{c}{ ratio } \\
\hline Properties & $\mathrm{KOH} / \mathrm{CaCO}_{3}$ & $\mathrm{KOH} / \mathrm{CaO}$ & $\mathrm{KOH} / \mathrm{K}_{2} \mathrm{CO}_{3}$ \\
\hline Density $\left(\mathrm{g} / \mathrm{cm}^{3}\right)$ & 0.92 & 0.84 & 0.88 \\
Acid Value $(\mathrm{mg} \mathrm{KOH} / \mathrm{g})$ & 0.35 & 0.54 & 1.20 \\
Viscosity $\left(\mathrm{mm}^{2} / \mathrm{s} @ 40^{\circ} \mathrm{C}\right)$ & 2.71 & 2.20 & 2.40 \\
Free fatty acid $(\%)$ & 0.30 & 0.84 & 0.88 \\
Yield $(\%)$ & 95.69 & 63.40 & 59.02 \\
\hline
\end{tabular}

Table 4: Properties of biodiesel obtained with $15 \% \mathrm{KOH} / \mathrm{X}$ support catalyst with 1:3 oil/methanol ratio

\begin{tabular}{|c|c|c|c|}
\hline Properties & $\mathrm{KOH} / \mathrm{CaCO}_{3}$ & $\mathrm{KOH} / \mathrm{CaO}$ & $\mathrm{KOH} / \mathrm{K}_{2} \mathrm{CO}_{3}$ \\
\hline Density $\left(\mathrm{g} / \mathrm{cm}^{3}\right)$ & 0.94 & 1.01 & 0.94 \\
\hline Acid Value (mg KOH/g) & 0.14 & 1.28 & 1.11 \\
\hline Viscosity $\left(\mathrm{mm}^{2} / \mathrm{s} @ 40^{\circ} \mathrm{C}\right)$ & 2.40 & 2.00 & 2.23 \\
\hline Free fatty acid (\%) & 0.11 & 0.65 & 0.62 \\
\hline Yield $(\%)$ & 89.45 & 53.40 & 49.02 \\
\hline
\end{tabular}

Table 5: Properties of biodiesel obtained with $20 \% \mathrm{KOH} / \mathrm{X}$ support catalyst with 1:3 oil/methanol

\begin{tabular}{|c|c|c|c|}
\hline Properties & $\mathrm{KOH} / \mathrm{CaCO}_{3}$ & $\mathrm{KOH} / \mathrm{CaO}$ & $\mathrm{KOH} / \mathrm{K}_{2} \mathrm{CO}_{3}$ \\
\hline Density $\left(\mathrm{g} / \mathrm{cm}^{3}\right)$ & 1.41 & 1.28 & 1.11 \\
\hline Acid Value (mg KOH/g) & 0.12 & 1.18 & 1.05 \\
\hline Viscosity ( $\left.\mathrm{mm}^{2} / \mathrm{s} @ 40^{\circ} \mathrm{C}\right)$ & 2.36 & 2.02 & 1.88 \\
\hline Free fatty acid (\%) & 0.06 & 0.45 & 0.33 \\
\hline
\end{tabular}


Yield $(\%)$

86.05

51.85

48.02

Table 6: Yields obtained from transesterification with the $10 \%$ catalyst

\begin{tabular}{lllll} 
& \multicolumn{4}{c}{$\mathrm{KOH} / \mathrm{CaCO}_{3}$} \\
\hline Oil/methanol ratio & $1: 5$ & $1: 10$ & $1: 20$ & $1: 30$ \\
Density $\left(\mathrm{g} / \mathrm{cm}^{3}\right)$ & 1.54 & 2.48 & 3.00 & 3.11 \\
Acid Value $(\mathrm{mg} \mathrm{KOH} / \mathrm{g})$ & 0.31 & 0.25 & 0.19 & 0.15 \\
Viscosity $\left(\mathrm{mm}^{2} / \mathrm{s} \mathrm{@} 40^{\circ} \mathrm{C}\right)$ & 3.32 & 3.76 & 4.12 & 4.55 \\
Free fatty acid $(\%)$ & 0.27 & 0.24 & 0.20 & 0.20 \\
Yield $(\%)$ & 95.80 & 98.12 & 94.22 & 94.15 \\
\hline
\end{tabular}

\subsection{Discussion}

\subsubsection{Properties of the waste cooking oil}

The physico-chemical properties of the waste oil used in this research works are as shown on Table 1. Analysis on the oil showed that the WCO had density of $0.92 \mathrm{~g} / \mathrm{cm} 3$, acid value of $1.57 \mathrm{mg} \mathrm{KOH} / \mathrm{g}$, water content of $0.84 \%$, value of free fatty acid present was found to be $3.04 \%$ with viscosity equals to $31.20 \mathrm{~mm}^{2} / \mathrm{s}$. These properties revealed the level of usage of the vegetable oils. Some of these oil properties are likely indicators of the properties of biodiesel produced from the oils. Of these properties, it is the increase in the FFA that has the most limiting effect on the use of waste oil as a raw material for biodiesel production (Wang et al., 2018). High FFA oils result in the consumption of a portion of the oil to form soap instead of biodiesel during trans-esterification. As can be seen in table 1, the waste cooking oil has properties much different from those from the neat oil. For example, WCO possess much higher acid value than neat oil which indicates the high presence of free fatty acid and so will hydrolyse more easily, hence could not be converted to biodiesel using an alkaline catalyst.

Kumar et al. (2018) stated that the high temperature of typical cooking processes and water from the foods accelerate the hydrolysis of triglycerides and increase the free fatty acid content in the oil. However, some researchers reported that base catalyst can tolerate higher content of FFA. Nevertheless, it is clear that the FFA content in oil feedstock should be as low as possible (ranging from less than $0.5 \mathrm{wt} \%$ to less than $4 \mathrm{wt} \%$ ) for base catalyzed transesterification reaction (Lam et al., 2010).

\subsubsection{Biodiesel Yields obtained from different catalyst loading with 1:3 oil/methanol ratios}

The results of the biodiesel yield obtained from the transesterification of WCO with different catalyst loading (under the same experimental conditions) are shown in Table $2-5$. Higher biodiesel yields (95.69\%) were obtained with $10 \% \mathrm{KOH} / \mathrm{CaCO}_{3}$ catalyst. With $10 \%$ of support catalysts, the forward reaction of transesterification process was faster, resulting in higher percentage conversion under similar reaction conditions of temperature and time with other catalyst loading. The overall results indicated that a biodiesel yield increases in the order of $\mathrm{KOH} / \mathrm{K}_{2} \mathrm{CO}_{3}>\mathrm{CaO}>\mathrm{KOH} / \mathrm{CaCO}_{3}$. This can be related to the basic nature of these catalysts as $\mathrm{KOH} / \mathrm{K}_{2} \mathrm{CO}_{3}$ is more basic than the others. The percentage yield is inversely proportional to the FFA, i.e. the lower the FFA the higher the percentage yield and the higher the alkalinity of the catalyst the lower the yield. This is because FFA reacts with alkali catalysts to produce soaps that inhibit the reaction.

Triglycerides conversion increased markedly with an increase in the amount of catalyst support from $5 \mathrm{wt} \%$ up to $10 \mathrm{wt} \%$ indicating that as the catalyst loading increases, the number of active catalytic sites increases and a shorter time is required for the reaction to reach the equilibrium (optimum). Beyond that, the change is marginal decreasing. According to the Madon and Boudart test (Kumar et al., 2018; Yang et al., 2019), a modified form of the Koros and Nowak test (Gaurav et al., 2017), in the absence of any mass transfer limitations, the oil conversion should increase proportionately with the amount of the catalyst. We observed this increase in the range of $5-10 \mathrm{wt} \%$ catalyst support. The deviation from this linearity beyond $10 \mathrm{wt} \%$ of the catalyst indicates that, at higher catalyst support concentrations, there exists mass transfer limitation on the reaction rate. At the chosen reaction time $(5 \mathrm{~h})$, conversions are also influenced by equilibrium attainment. The non-homogeneity of the slurry at such high concentrations of the solid catalyst may also contribute to such a mass transfer limitation. 


\subsubsection{Properties of biodiesel produced with $1: 3 \mathrm{oil} /$ methanol ratio}

The physical and chemical analyses of the biodiesel produced from WCO were conducted and the results are presented in Table 1-5. The results of the experiments show that transesterifications of the waste oils using $\mathrm{KOH} / \mathrm{CaCO}_{3}$ as catalyst produced better properties compared with those obtained from $\mathrm{KOH} / \mathrm{CaO}$ and $\mathrm{KOH} / \mathrm{K}_{2} \mathrm{CO}_{3}$ catalysed transesterifications.

Density is the weight per unit volume of a material measured in $\mathrm{g} / \mathrm{cm}^{3}$. Oils that are denser contain more energy. For example, petrol and diesel fuels give comparable energy by weight, but diesel is denser and hence gives more energy per litre. Biodiesel from $20 \% \mathrm{KOH} / \mathrm{CaCO}_{3}$ catalyst support gave the highest density of $1.41 \mathrm{~g} / \mathrm{cm}^{3}$ while $5 \% \mathrm{KOH} / \mathrm{K}_{2} \mathrm{CO}_{3}$ gave the lowest density of $0.78 \mathrm{~g} / \mathrm{cm}^{3}$. The standard density range for biodiesel is $0.86-0.90$ and $0.81-0.86$ for petroleum diesel. This shows that the biodiesel produced have densities within the standard range with $10 \% \mathrm{KOH} / \mathrm{CaCO}_{3}$ catalyst support giving the best result. Density is an essential parameter for diesel fuel injection systems and so, the value should be maintained within the tolerable limits to allow optimal air to fuel ratio for complete combustion.

The acid values of the biodiesels were determined and the values obtained ranged between 0.12 to $1.50 \mathrm{mg} \mathrm{KOH} / \mathrm{g}$ for all the samples. These values are in agreement with the ASTM specification for biodiesel which is $0.5 \mathrm{mg} \mathrm{KOH} / \mathrm{g}$ maximum. This makes the biodiesel of WCO good for the engine because the presence of free fatty acids in biodiesels more than this amount can lead to corrosion of engine wares and the presence of the free fatty acids could be increased as a result of water in the fuel.

Viscosity is a measure of a fluid's resistance to flow. It describes the internal friction of a moving fluid. A fluid with high viscosity resists motion because its molecular structure gives it a lot of internal friction, while fluid with low viscosity flows easily due to its molecular structure which results in very little friction when it is in motion, the less viscous the fluid is, the greater its ease of movement (fluidity). For the case of liquid fuels, viscosity refers to the thickness of the oil, and is determined by measuring the amount of time taken for a given measure of oil to pass through an orifice of a specified size. Viscosity affects injector lubrication and fuel atomization. Fuels with low viscosity may not provide sufficient lubrication for the precision fit of fuel injection pumps, resulting in leakage or increased wear; conversely fuels with high viscosity tend to form larger droplets on injection which can cause poor combustion, increased exhaust smoke and emissions.

The results obtained showed that the viscosity values obtained for all the different catalyst type were within the recommended ASTM range of 1.9 to $6.0 \mathrm{~mm}^{2} / \mathrm{s}$ for biodiesel at reference temperatures, $40^{\circ} \mathrm{C}$. The highest value viscosity obtained is $2.80 \mathrm{~mm}^{2} / \mathrm{s}$ from $5 \% \mathrm{KOH} / \mathrm{CaO}$ catalyst, while the lowest value is $1.88 \mathrm{~mm}^{2} / \mathrm{s}$ from $20 \% \mathrm{KOH} / \mathrm{K}_{2} \mathrm{CO}_{3}$. This means the biodiesels are suitable for use in a diesel engine, because of their moderate viscosity value as high viscosity values affect the fuel fluidity that lead to poor atomization of fuel spray and subsequently give an inaccurate operation of the fuel injectors.

\subsubsection{Effects of oil/methanol mole ratio}

For all further transesterification study, $10 \mathrm{wt} \% \mathrm{KOH} / \mathrm{CaCO}_{3}$ was chosen as the optimum catalyst loading to have given the best biodiesel product with 1:3 oil/methanol ratio. The molar ratio between oil and alcohol is one of the main factors that influence the conversion of triglyceride. Theoretically, the reaction stoichiometry requires three moles of alcohol per mole of triglycerides to yield three moles of biodiesel and one mole of glycerine. However, in practice, a higher feed mole ratio is employed in order to shift the esterification reaction to better desired product.

Table 6 shows the effect of feed mole ratio of WCO to methanol on the conversion of triglycerides. As observed from the table, the conversion of triglycerides increased with an increase in oil to methanol feed mole ratio from 1:5 to 1:10 which are 95.80 and $98.12 \%$ respectively. Further increase in feed mole ratio of oil to methanol from 1:10 to 1:20 and 1:30 did not result in an increase in conversion of triglycerides and the final triglycerides conversion for both feed mole ratios were approximately same, i.e. 94.22 and $94.15 \%$ respectively. A significantly high feed mole ratio is not 
preferable in biodiesel production because it makes the separation process difficult (Javed, et al., 2019). A higher consumption of methanol also requires larger unit operations including reactors, separation column and methanol recovery equipment that will increase the overall cost of the process (Muhammad et al., 2018; Yang and Brammer, 2010).

An optimum operating ratio for this study has be selected on the basis of overall equilibrium conversion with better quality in terms of density, acid value, viscosity and free fatty acid. Therefore, a feed mole ratio of 1:10 oil to methanol was observed as the optimum ratio in the biodiesel production. The use of high methanol/oil (higher than 10) mole ratio, did not favour biodiesel production; rather it pushed the reversible reaction to the right side of the reaction equation. Anwar $e t$ al. (2021) however reported that when too much alcohol is used in transesterification, the polarity of the reaction mixture is increased, thus increasing the solubility of glycerol and promotes the reverse reaction between glycerol and biodiesel, thereby reducing biodiesel yield.

\subsection{Conclusions}

Transesterification of WCO using various types of heterogeneous catalysts (viz a viz $\mathrm{KOH} / \mathrm{CaCO}_{3}$, $\mathrm{KOH} / \mathrm{CaO}$ and $\mathrm{KOH} / \mathrm{K}_{2} \mathrm{CO}_{3}$ ) has been investigated. Under the same condition, among the catalysts tested that is $\mathrm{KOH} / \mathrm{CaCO}_{3}$ and $\mathrm{KOH} / \mathrm{CaO}$ indicated lower performance while $\mathrm{KOH} / \mathrm{CaCO}_{3}$ catalyst showed the best catalytic performance in terms of $\%$ yield and better fuel quality in density, acid value, viscosity and free fatty acid. The reason for this performance may be due to it more basic character than the others. As a result, this was selected for the optimisation study. At the optimum reaction conditions of $10 \mathrm{wt} \%$ catalyst concentration and 1:10 oil to methanol feed mole ratio, triglycerides conversion was $98.12 \%$.

The chemical and physical characterisation of purified biodiesel has been carried out. The characterisation results show that the parameters tested (i.e. density, viscosity, acid value and free fatty acid). The quality of the biodiesel is in total agreement with the ASTM standard.

This study is useful in identifying better ways of waste management. With the staggering population of Nigeria and establishment of more food restaurants, coupled with the corresponding need for survival, waste cooking oil will be continuously generated and rather than constituting more problems to the environment, its conversion to biodiesel is therefore highly recommended.

\section{References}

Africa Energy World Report (2019). World Energy Outlook special report. Retrieved November, 10 November, 2021 from https://www.iea.org/reports/africa-energy-outlook-2019.

Anwar, M. K., Sophia B., Joanna, C., Amy, F., Rayne, H., James, C. M., et al. (2021). Investigation of Biofuel as a Potential Renewable Energy Source. Atmosphere, 12(10), pp. 1289-1312.

ASTM (2017). Standard Test Method for Acid and Base Number by Color-Indicator Titration. In: Annual Book of ASTM Standards, ASTM International, West Conshohocken, Method D974-02

ASTM (2018). Standard Test Method for Flash and Fire Points by Cleveland Open Cup Tester. In: Annual Book of ASTM Standards, ASTM International, West Conshohocken, Method D92-16b

ASTM (2019). Standard Test Method for Density, Relative Density, and API Gravity of Liquids by Digital Density Meter. In: Annual Book of ASTM Standards, ASTM International, West Conshohocken, Method D4052-18a

ASTM (2020a). Standard Specification for Biodiesel Fuel Blend Stock (B100) for Middle Distillate Fuels. In: Annual Book of ASTM Standards, ASTM International, West Conshohocken, Method D6751-02 
ASTM (2020b). Standard Test Method for Kinematic Viscosity of Transparent and Opaque Liquids by Automated Houillon Viscometer. In: Annual Book of ASTM Standards, ASTM International, West Conshohocken, Method D7279-20

ASTM (2020c). Standard Test Methods for Flash Point by Pensky-Martens Closed Cup Tester. In: Annual Book of ASTM Standards, ASTM International, West Conshohocken, Method D93-19

Atadashi, I. M., Aroua, M. K., Abdul Aziz, A. R. and Sulaiman, N. M. N. (2011). Refining technologies for purification of crude biodiesel. Applied Energy, 88, pp. 4239-4251.

Bianchi, C. L., Bofeto, D. C., Pirola, C. and Ragaini, V. (2010). Low temperature de-acidication process of animal fat as a pre-step to biodiesel production. Catal. Lett. 134, pp. 179-183.

Choi, Y. Y., Patel, A. K., Hong, M. E., Chang, W. S. and Sim, S. J. ( 2019). Microalgae Bioenergy with Carbon Capture and Storage (BECCS): An emerging sustainable bioprocess for reduced CO2 emission and biofuel production. Bioresour. Technol. Rep., 7, p. 100270.

Chozhavendhan, S., Vijay, M.P.S., Fransila, B., Praveen R.K., Karthiga, G.D. (April 2020). A review on influencing parameters of biodiesel production and purification processes. Current Research in Green and Sustainable Chemistry, 1-2, pp. 1-6.

Felix, I., Damola, A., Angela, M., Temitope, A., Abraham, A., Obafemi, O., Stephen, A.(2020). Biodiesel production from palm olein: A sustainable bioresource for Nigeria.Heliyon, 6(4),1-12

Gaurav, N., Sivasankari, S., Kiran, G. S., Ninawe, A. and Selvin, J. (2017). Utilization of bioresources for sustainable biofuels: A Review. Renew. Sust. Energ. Rev., 73, pp. 205-214.

Javed, F., Aslam, M., Rashid, N., Shamair, Z., Khan, A. L., Yasin, M., et al.(2019). Microalgaebased biofuels, resource recovery and wastewater treatment: A pathway towards sustainable biorefinery. Fuel, 255, p. 115826.

Knothe, G. (2001).Analytical methods used in the production and fuel quality assessment of biodiesel. Chemistry. Transactions of the ASAE, 44(2), pp. 193-200. doi:10.13031/2013.4740

Kotwal, M. S., Niphadkar, P. S., Deshpande, S. S., Bokade, V. V. and Joshi, P. N. (2009). Transesterification of sunflower oil catalyzed by flyash-based solid catalysts. Fuel, 88, pp. 1773-1778.

Kumar, V., Nanda, M., Joshi, H. C., Singh, A., Sharma, S. and Verma, M. (2018). Production of biodiesel and bioethanol using algal biomass harvested from fresh water river. Renew. Energy, 116, pp. 606-612.

Lam, M. K., Lee, K. T. and Mohamed, A. R. (2010). Homogeneous, heterogeneous and enzymatic catalysis for transesterification of high free fatty acid oil (waste cooking oil) to biodiesel: A review. Journal of Biotechnology Advances, 28(4), p. 500.

Leung, D. Y. and Guo, Y. (2006). Trans-esterification of Neat and Used Frying Oil: Optimization for Biodiesel Production. Fuel Processing Technology, 87, pp. 883 - 890.

Michael I. L., Xenia I. L., Demetra L. O. and Demetra P. (2019). Circular Bioeconomy in Action: Collection and Recycling of Domestic Used Cooking Oil through a Social, Reverse Logistics System. Recycling, 4(16), pp. 1-10.

Muhammad, U. L., Shamsuddin, I. M., Danjuma, A., Musawa, R. S. and Dembo, U. H. (2018). Biofuels as the starring substitute to fossil fuels. Pet. Sci. Eng., 2, pp. 44-49. 
Özbay, N., Oktar, N. and Alper Tapan, A. (2008). Esterification of free fatty acids in waste cooking oils(WCO): Role of ion-exchange resins. Fuel, 87, pp. 1789-1798.

Phebe, A. O. and Samuel, A. S. (2016). A review of renewable energy sources, sustainability issues and climate change mitigation. Cogent Engineering, 3(1), pp. 1-14.

Subramaniam, Y., Masron, T. A. and Azman, N. H. N. (2020). Biofuels, environmental sustainability and food security: A review of 51 countries. Energy Res. Soc. Sci., 68, p. 101549.

Tombari, B., Gbidum, B. and Kemetonye, J .(2020). Illegal Oil Bunkering in the Niger Delta Region of Nigeria: A Challenge to Nigeria's Development. European Scientific Journal, 16(29), pp. 18577881.

Wang, M., Chen, M., Fang, Y. and Tan, T. (2018). Highly efficient conversion of plant oil to bioaviation fuel and valuable chemicals by combination of enzymatic transesterification, olefin crossmetathesis, and hydrotreating. Biotechnol. Biofuels, 11, pp. 1-9.

William, H. K. (2006). Biodiesel: Basics and Beyond - A Comprehensive Guide to Production and Use for the Home and Farm. Aztext Press, 2622 Mountain road, Tamworth, Ontario Canada. ISBN-13: 978-0-9733233-3-7.

Yang, J., Xin, Z., He, Q., Corscadden, K. and Niu, H. (2019). An overview on performance characteristics of bio-jet fuels. Fuel, 237, pp. 916-936.

Yang, Y. and Brammer, J. (2010). Biomass pyrolysis oil as a diesel engine fuel. European Bioenergy Research Institute (EBRI), Aston University, Birmingham, UK. 